\title{
Thoracic spine pain in the general population: Prevalence, incidence and associated factors in children, adolescents and adults. A systematic review
}

\author{
Andrew M Briggs ${ }^{1}$, Anne J Smith ${ }^{1}$, Leon M Straker*1 and Peter Bragge ${ }^{2}$
}

Address: ${ }^{1}$ School of Physiotherapy and Curtin Health Innovation Research Institute, Curtin University of Technology, GPO Box U1987, Perth, 6845, Western Australia, Australia and ${ }^{2}$ Global Evidence Mapping (GEM) Initiative, Department of Surgery (Royal Melbourne Hospital), University of Melbourne, Parkville 3010 VIC, Australia

Email: Andrew M Briggs - A.Briggs@curtin.edu.au; Anne J Smith - Anne.Smith@exchange.curtin.edu.au;

Leon M Straker* - L.Straker@curtin.edu.au; Peter Bragge - pbragge@unimelb.edu.au

* Corresponding author

Published: 29 June 2009

BMC Musculoskeletal Disorders 2009, 10:77 doi:10.1186/147|-2474-10-77
Received: 19 February 2009

Accepted: 29 June 2009

This article is available from: http://www.biomedcentral.com/I47/-2474//0/77

(C) 2009 Briggs et al; licensee BioMed Central Ltd.

This is an Open Access article distributed under the terms of the Creative Commons Attribution License (http://creativecommons.org/licenses/by/2.0), which permits unrestricted use, distribution, and reproduction in any medium, provided the original work is properly cited.

\begin{abstract}
Background: Thoracic spine pain (TSP) is experienced across the lifespan by healthy individuals and is a common presentation in primary healthcare clinical practice. However, the epidemiological characteristics of TSP are not well documented compared to neck and low back pain. A rigorous evaluation of the prevalence, incidence, correlates and risk factors needs to be undertaken in order for epidemiologic data to be meaningfully used to develop evidence-based prevention and treatment recommendations for TSP.

Methods: A systematic review method was followed to report the evidence describing prevalence, incidence, associated factors and risk factors for TSP among the general population. Nine electronic databases were systematically searched to identify studies that reported either prevalence, incidence, associated factors (cross-sectional study) or risk factors (prospective study) for TSP in healthy children, adolescents or adults. Studies were evaluated for level of evidence and method quality.

Results: Of the 1389 studies identified in the literature, 33 met the inclusion criteria for this systematic review. The mean (SD) quality score (out of I5) for the included studies was 10.5 (2.0). TSP prevalence data ranged from 4.0-72.0\% (point), 0.5-5I.4\% (7-day), I.4-34.8\% (I-month), 4.8-7.0\% (3-month), 3.5$34.8 \%$ (I-year) and $15.6-19.5 \%$ (lifetime). TSP prevalence varied according to the operational definition of TSP. Prevalence for any TSP ranged from $0.5-23.0 \%$, 15.8-34.8\%, $15.0-27.5 \%$ and $12.0-31.2 \%$ for 7 -day, I-month, I-year and lifetime periods, respectively. TSP associated with backpack use varied from 6.0 $72.0 \%$ and $22.9-51.4 \%$ for point and 7-day periods, respectively. TSP interfering with school or leisure ranged from $3.5-9.7 \%$ for I-year prevalence. Generally, studies reported a higher prevalence for TSP in child and adolescent populations, and particularly for females. The I month, 6 month, I year and 25 year incidences were $0-0.9 \%, 10.3 \%, 3.8-35.3 \%$ and $9.8 \%$ respectively. TSP was significantly associated with: concurrent musculoskeletal pain; growth and physical; lifestyle and social; backpack; postural; psychological; and environmental factors. Risk factors identified for TSP in adolescents included age (being older) and poorer mental health.

Conclusion: TSP is a common condition in the general population. While there is some evidence for biopsychosocial associations it is limited and further prospectively designed research is required to inform prevention and management strategies.
\end{abstract}




\section{Background}

Spinal pain is a well recognised condition associated with significant personal and community burdens. The most common spinal regions studied are the lumbar and cervical spine, probably because of their strong and well-established associations with pain conditions, work-related injuries, intervertebral disc degenerative conditions, headaches and psychosocial disturbances [1,2]. Compared to the lumbar and cervical spine, the thoracic spine has received less attention in terms of clinical, genetic and epidemiologic research $[3,4]$, yet pain experienced in the thoracic spine can be equally disabling, imposing similar burdens on the individual, community [4-6] and workforce [7]. In the context of this paper, we refer to thoracic spine pain (TSP) as pain experienced in the region of the thoracic spine, between the boundaries of T1-T12 and across the posterior aspect of the trunk. TSP may arise from a number of sources including thoracic and cervical spinal structures, the thorax, and the gastrointestinal, cardiopulmonary and renal systems $[3,8,9]$. Moreover, the thoracic spine is a common site for inflammatory, degenerative, metabolic, infective and neoplastic conditions which may also contribute to pain and disability [10].

The limited research on prevalence and risk factors for TSP likely reflects the belief that the clinical and public health significance of TSP is less compared to other spinal levels. Nonetheless, it has been argued that TSP should be considered as a discrete and important clinical entity, independent of pain experienced in other areas of the spine [11], and particularly in youth where TSP is common, disabling and has an increasing incidence with age during adolescence $[11,12]$. There is also evidence to suggest that pain or dysfunction in the thoracic spine is not trivial in adulthood [13]. Alarmingly, preliminary evidence suggests the incidence of spinal pain among otherwise healthy adolescents is increasing, which may suggest a new and expanding condition burden for future adults [14]. More international studies are required to verify whether an increasing incidence is a global phenomenon. This highlights the importance of examining modifiable risk and prognostic factors for spinal pain, including TSP, from childhood to adulthood.

TSP and dysfunction are associated with conditions such as primary and secondary osteoporosis, particularly vertebral fractures [15-18] and hyperkyphosis arising from vertebral bone loss [19], ankylosing spondylitis [20], osteoarthritis [21] and Scheuermann's disease [22]. However, little attention has been paid to TSP among individuals who have no history of a metabolic, inflammatory or structural disorder, despite such non-specific, mechanical TSP being a common presentation in clinical practice [23]. Similar to the lumbar spine, degenerative signs identified in the thoracic spine with imaging modalities are not necessarily associated with pain, suggesting that nonspecific TSP is also prevalent $[3,24]$.

Understanding the prevalence and risk factors of TSP in the otherwise healthy general population is important for several reasons. Firstly, musculoskeletal dysfunction in this population is likely to impose a significant community burden, particularly when considering reduced productivity in young-adult and middle-aged working populations. Secondly, interpretation of TSP in disease needs to be evaluated against normative populationbased data. Thirdly, such information can be harnessed to develop evidence-based preventative and treatment strategies for this condition. Emerging evidence from crosssectional and prospective cohort studies, as cited in this paper, suggests that TSP is prevalent among healthy individuals and does impact on function $[4,11,13]$, yet to our knowledge no reviews have been published which evaluate and synthesise these data from childhood to adulthood. Although an earlier review reported the prevalence and incidence of idiopathic TSP in youth, no data were included on adult cohorts nor were any correlates or risk factors for TSP reported, a small number of databases were searched, and the included studies were not critically appraised [25]. Here, we extend the findings of that review by including adults and address the abovementioned limitations. A major limitation of previous research is the use of a combined outcome measure for spinal pain. That is, specific results for the thoracic spine are rarely reported. Rather, only low back or just 'back' pain is reported which may encompass more than one spinal area. A similar limitation has also been identified in an earlier systematic review of neck pain [26], while other authors argue that a standardised definition of spinal pain is urgently needed which specifies time period recall, symptoms and anatomical areas [27-29]. Therefore, the aim of this review was to systematically review and report evidence describing the prevalence, incidence, associations (cross-sectional study) and risk factors (prospective study) for TSP in the general population outside the context of late adulthood and who are free of other pathology.

\section{Methods}

A systematic review method was used to address the aim of this study. Systematic reviews use explicit search, study selection and appraisal methods to address a focused clinical question [30]. Systematic reviews are less prone to bias than narrative reviews, in which non-systematic approaches to searching, selection and appraisal are employed [31]. The structure and content of this systematic review complies with recommendations outlined by the Meta-analysis of Observational Studies in Epidemiology (MOOSE) group for reporting meta-analyses of observational studies [32]. 


\section{Data sources and searches}

Nine databases (Medline, CINAHL, PubMed, ISI Web of Science, PEDro, EMBASE, Cochrane, AMED, BioMed Central) were searched using search strings listed in Appendix 1, from inception to January 2008. Automatic search alerts were set up in each database to alert the authors to any new papers published which met the search criteria between January 2008 and February 2009; however, no further papers were identified during this period. In addition, reference lists of included papers were searched to identify other potentially suitable studies. Shorter and simpler search strings were used for databases that did not use subject headings or that had a limited number of allowable search terms (Cochrane, PEDro, BioMed Central). Search strings pertaining to prevalence and risk factors were based on a previously conducted systematic review of prevalence and risk factors for musculoskeletal disorders [33]. In addition, keywords were mapped to subject headings (MeSH headings) in MEDLINE to identify synonyms for 'epidemiological', 'thoracic spine' and 'musculoskeletal disorder' terms.

\section{Study selection}

For studies to be included in this review, the following criteria had to be met:

1. The cohort (children, adolescents or adults) had to be community-based so that cohorts studied were population-based, rather than specific to certain occupational, clinical, or athletic groups. For example, studies which reported TSP characteristics among a cohort of individuals with osteoporosis or other musculoskeletal pathologies or diagnosed structural deformities (e.g. scoliosis) were excluded. Therefore only idiopathic presentations of TSP in the general population were included.

2. The study had to report either prevalence, incidence, associated factors, or risk factors for thoracic spine pain specifically (cervico-thoracic and thoraco-lumbar were also accepted). The outcome variables could be self-reported or clinically evaluated. Any self-reported pain experienced in the thoracic spine, dorsal spine, upper back or mid-back was accepted and no inclusion criteria were imposed pertaining to pain severity, frequency, duration or pain-related disability as there are no agreed criteria for these in the context of TSP.

3. The study design had to be case-control, cross-sectional or cohort (prospective-cohort or retrospectivecohort). Case-control and cross-sectional studies are appropriate for investigating prevalence and correlates, while prospective or retrospective cohort studies are appropriate for investigating incidence and risk factors $[34,35]$.
4. The study had to be published in a peer-reviewed journal in English.

Titles and abstracts of citations were assessed for inclusion eligibility by two independent reviewers (AB, AS), both experienced musculoskeletal science researchers. Full text articles appearing to meet the above criteria were retrieved and evaluated against the inclusion criteria. Full text articles were also retrieved and evaluated in circumstances where the abstract was not available, or if it was not clear whether the article met the inclusion criteria for the review based on the content of the abstract. Disagreement regarding eligibility for inclusion, at the level of both title/ abstract and full text review, was resolved by a consensus meeting between the authors. Figure 1 illustrates the systematic review process for this paper.

\section{Data extraction and quality assessment}

Study quality was assessed using two methods by two independent reviewers (AB, AS). First, the study design of each eligible study was ranked using the revised Australian National Health and Medical Research Council (NHMRC) Hierarchy of Evidence framework [35] (Appendix 2). We considered this hierarchy to be appropriate as it comprises levels of evidence for each type of research question (intervention, diagnostic accuracy, prognosis, aetiology, screening intervention). For this review, we considered the hierarchy of evidence for 'aetiology' to be the most appropriate category. Hierarchical ranking provides a broad indication of the methodological strength of a study.

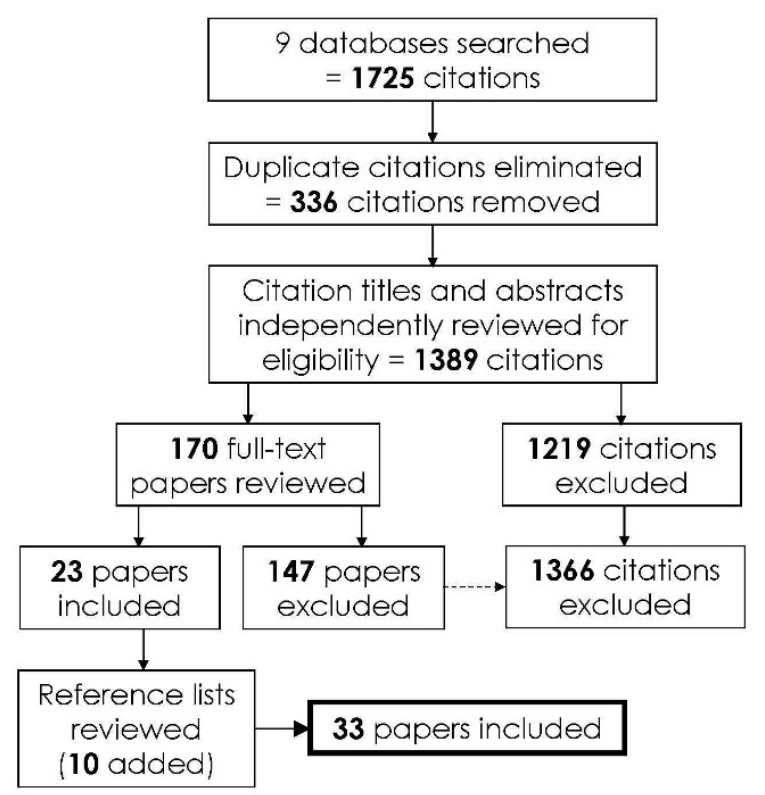

Figure I

Flowchart illustrating process for systematic review and assessing inclusion criteria. 
Second, an in-depth appraisal of method quality was conducted using the Critical Review Form - Quantitative Studies [36]. This appraisal tool evaluates method rigor and bias using a combination of dichotomous (yes/no) and descriptive items. The descriptive items are listed at the foot of Additional file 1. The decision to select a yes/ no score was based on the experience of the raters, instructions accompanying the tool, and applicability of the domains relative to the design of the study being appraised. Any disagreements in dichotomous scores between the independent reviewers were resolved by consensus. An arbitrary quality score was obtained by sumtotalling 15 relevant dichotomous quality appraisal criteria in this tool, with a score of 1 indicating fulfilment of the criterion and a score of 0 indicating non-fulfilment or non-description of the criterion. Thus, a higher score represented higher method quality. This critical appraisal tool was chosen because:

a) It evaluates the domains 'appropriate selection of participants' and 'appropriate measurement of variables'. These domains have been recommended as fundamental to an observational epidemiological critical appraisal tool, given that there is no consensus in the literature regarding a 'gold standard' appraisal tool for observational epidemiological studies [37].

b) It can be used for a variety of study designs, including epidemiological studies, as reflected by previously published epidemiological systematic reviews that have employed this tool $[33,38]$. The use of a generic, rather than a design-specific critical appraisal tool facilitates comparison of methodological quality items common to different study designs (such as reliability and validity of outcome measurement) across the included studies.

c) Detailed instructions for use are provided, facilitating consistency in their interpretation and application [38].

\section{Data synthesis and analysis}

The following data were extracted by the chief author $(\mathrm{AB})$ : cohort characteristics including ethnicity, participant numbers and gender, age; mode of TSP data collection; prevalence and incidence of TSP as percentages; associations (cross-sectional studies) and risk factors (prospective studies) for TSP as either odds ratios, correlation co-efficients, chi square, regression, or Mann Whitney Utest statistics, depending on the analysis methods used in the source papers. Where data were presented in a Figure, the corresponding author of the paper was contacted and asked to provide the dataset. In circumstances where the data set was not available, data were interpolated from the
Figure. Results of the included studies were narratively synthesised.

\section{Results}

\section{Searching and inclusion}

Of the 1389 citations retrieved from the 9 databases searched (Appendix 3), 23 (1.7\%) [11-13,39-58] were selected for review on the basis of meeting the inclusion criteria (Figure 1). 1366 (98.3\%) papers were excluded because TSP was not reported specifically. A further 10 papers were selected after reviewing reference lists of the included papers [59-68]. Therefore, 33 papers were included in the review.

\section{Study design and quality assessment}

Additional file 1 summarises the study design, cohort characteristics, method of TSP data collection, hierarchy of evidence score for studies of aetiology, and quality scores for each study.

Of the 33 papers included in the review, 26 (78.8\%) were cross-sectional surveys (NHMRC evidence level IV), 5 $(15.2 \%)$ were prospective cohort studies (NHMRC evidence level II) and 2 (6.0\%) were retrospective cohort studies (NHMRC evidence level III-2) [35] (refer to Appendix 2 for definitions of NHMRC ranks).

The mean (SD) quality score from evaluation of study quality using the Critical Review Form - Quantitative Studies [36] was 10.5 (2.0) out of 15. The most common method flaws identified according to the quality assessment tool were sampling biases (inadequate blinding for physical measures, response rates below $80 \%$ ), inadequate sample size justification (power calculations), lack of detail regarding informed consent and a lack of information regarding the reliability and validity of outcome measures used. On the other hand, all studies used an appropriate design to address the proposed research question and the vast majority reported data in terms of statistical significance (e.g. reporting a 95\% confidence interval for odds ratios or a $p$-value for correlation co-efficient), commented on the clinical importance of the findings, used appropriate analysis methods (ie the correct statistical test), reached appropriate conclusions given their results reported (i.e. did not comment on issues for which there were no data to support the claims), and the outcomes offered implications for clinical practice (Additional file 1).

\section{Data extraction and synthesis}

The majority of cohorts were European $(\mathrm{n}=25,75.7 \%)$, while Canadian/USA ( $\mathrm{n}=4,12.1 \%)$, New Zealand/Australian $(n=2,6.1 \%)$ and Asian $(n=2,6.1 \%)$ populations were less commonly studied. 
Additional file 2 summaries the prevalence and incidence data for TSP across age groups according to the operational definition of TSP used in each study. There was considerable variability in the operational definitions of TSP employed in the various studies. This contributed to the large prevalence and incidence ranges across ages. In particular, the point prevalence ranged from $4-72 \%$ with the lower limit derived from a study where TSP was defined as "any back pain" while the upper derived from a study where TSP was defined as "pain associated with backpack use". A similar situation was noted for 7-day and 1-year prevalence. Of the 33 studies, 19 (57.6\%) employed a pain definition as "any pain", while $4(12.1 \%)$ used "pain while carrying a backpack", 1 (3.0\%) used "pain interfering with school or leisure activities", 8 (24.2\%) defined pain with a specific duration and/or frequency and 1 $(3.0 \%)$ used "pain after work". TSP prevalence also varied with age. For example, the 1-month prevalence ranged from $1.4 \%$ in adults aged $40-69$ years to $34.8 \%$ in children aged 12 years.

There were 31 reports of TSP prevalence in 29 studies across 6 prevalence periods. There were $5(16.1 \%)$ reports of point prevalence, $8(25.8 \%) 7$-day prevalence, 6 (19.4\%) 1-month prevalence, 1 (3.2\%) 3-month prevalence, $7(22.6 \%)$ 1-year prevalence and $4(12.9 \%)$ lifetime prevalence. Generally, studies reported a higher prevalence for TSP in child and adolescent populations, and particularly for females. These data are summarised in Figure 2. There were 6 reports of TSP incidence in 5 studies across 5 incidence periods. Similarly, there was marked variability in the 1-year incidence data $(3.8-35.3 \%)$ which likely reflects differences in age and pain definitions between the studies. Generally, incidence of TSP was higher among females, other than at the ages of 16 and 17 where the incidence of TSP in adolescent boys was greater than girls in one study [12].

Additional file 3 summarises all associated and risk factors reported for TSP across 15 studies according to 7 biopsychosocial categories. Across the individual studies, TSP was significantly associated with concurrent musculoskeletal pain and, growth and physical, lifestyle and social, backpack, postural, psychological, and environmental factors. The majority of studies $(\mathrm{n}=13,85.7 \%)$ were cross-sectional in design, providing only evidence of association between factors and TSP. Two prospective studies established significant risks factor for the development of TSP. Having poorer mental health [69] and being an older compared to younger adolescent [12] were identified as risk factors for TSP in adolescence.

\section{Discussion}

To our knowledge this is the first systematic review of the prevalence, incidence, associated factors and risk factors for TSP among the general population. We elected to study and report all these epidemiologic characteristics to present a comprehensive picture of what is known about TSP in the general population. Findings are consistent with clinical anecdotes suggesting that TSP is common in the general population, particularly during adolescence, yet interpretation of the data are difficult due to heterogeneity. Despite the large ranges identified in TSP prevalence, predominantly as a result of variability in definitions of pain, these data support the contention that TSP is prevalent among youth. Whether it should be considered as a discrete and important clinical presentation in youth and perhaps treated as such [11], would depend on how often TSP coexists with other spinal pain conditions. Conversely, in adulthood there are insufficient data to draw a similar conclusion. Unfortunately, the data reviewed do not provide comprehensive information about the impact of TSP on function. Nonetheless, up to $10 \%$ of adolescents experienced TSP that interfered with school or leisure [45] and TSP prevalence seemed to be highest during backpack use. Although some data have been collected regarding associated and risk factors for the condition, these are relatively scarce, highlighting the need for further epidemiologic research directed towards this condition. Most importantly, a consistent approach with respect to defining pain characteristics and reporting prevalence and incidence data is urgently needed among researchers to allow meaningful comparisons between studies.

\section{Study design and quality assessment}

The NHMRC supports a 4-point rating scale (excellent, good, satisfactory, poor) for each of the 5 essential components of a body of evidence: evidence base, consistency of results, clinical impact, generalisability, and applicability [35]. The majority of studies included in this review were cross-sectional in design, limiting inferences about causality and prognosis for TSP. Thus, in terms of the evidence base reviewed (relating primarily to study design), it may be rated as poor according to NHMRC criteria. Prospective cohort studies are therefore required to provide a more robust evidence base for prognostic factors and the clinical course of the condition across the lifespan. Moreover, these studies would also provide important information to clinicians regarding the natural history of TSP and ultimately trajectories in certain clinical groups. Nonetheless, we suggest that the evidence presented is satisfactory with respect to consistency, clinical impact, generalisability and applicability. Generally, the method quality of the included studies was good, with only one older study being rated particularly low (4/15) [42]. More than 90\% of the studies reviewed used an appropriate study design, used appropriate analysis methods, reported results in terms of statistical significance, provided a commentary on the clinical relevance, and reached appropriate conclusions given the results presented. The most significant method quality issue identified was a lack of sample size 
Point prevalence

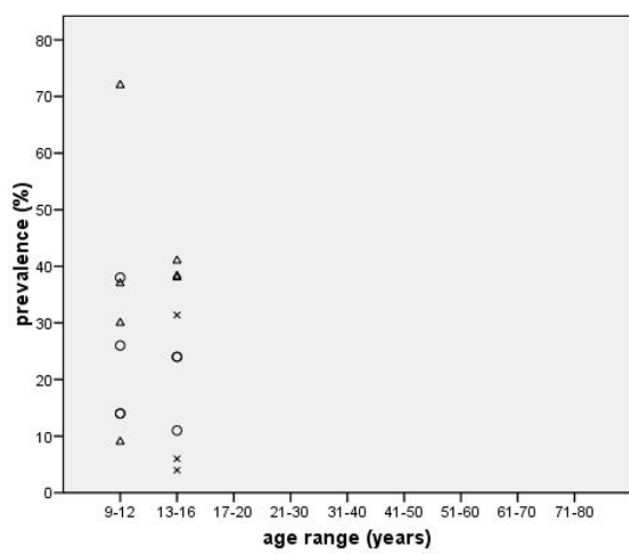

1 month prevalence

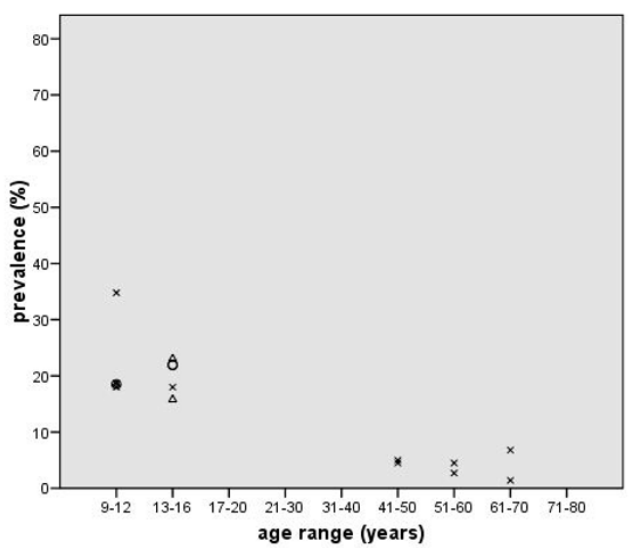

1 year prevalence

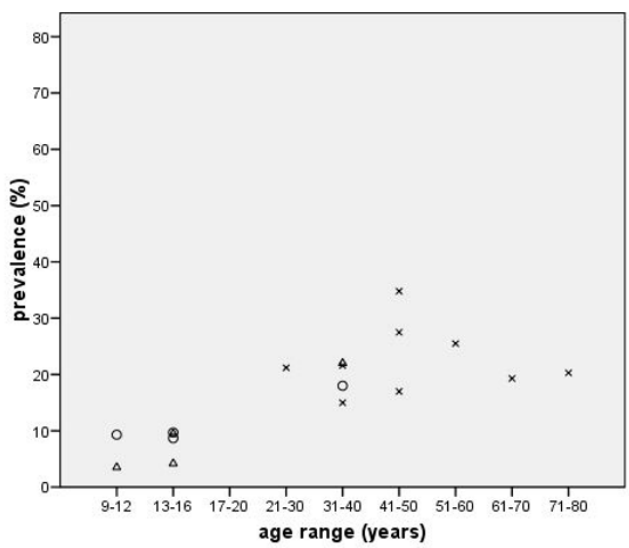

1 week prevalence

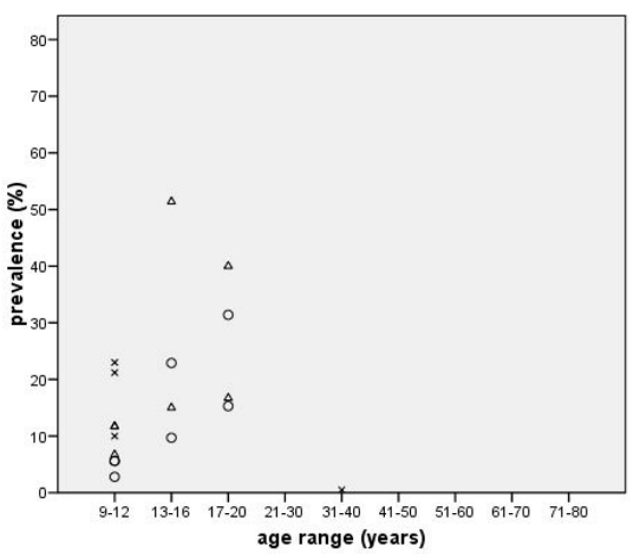

3 month prevalence

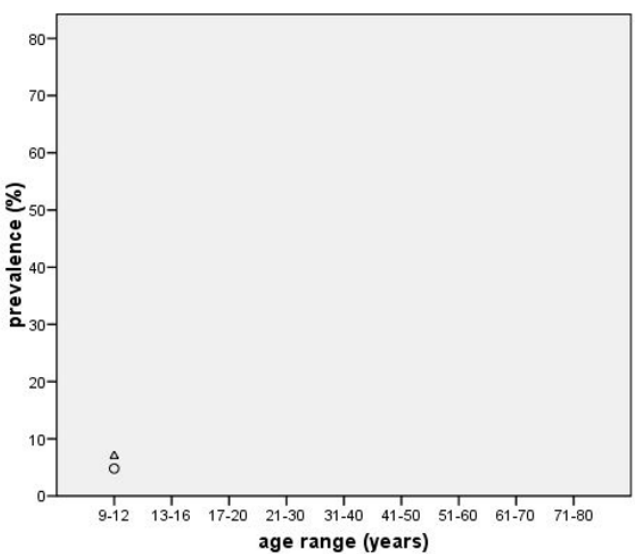

Lifetime prevalence

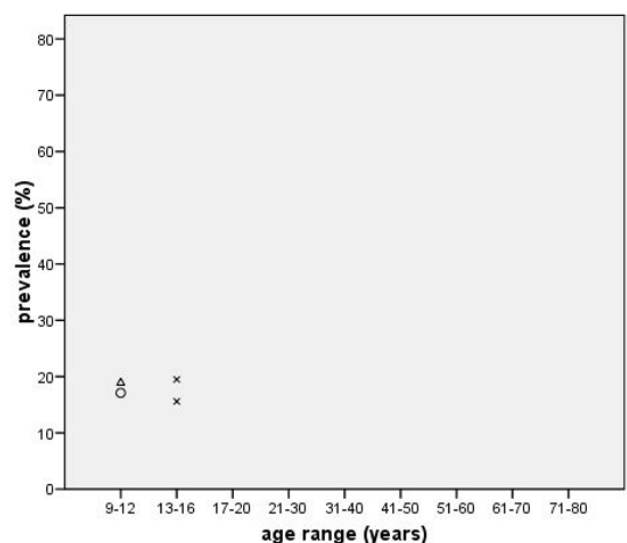

gender

Omale
$\triangle$ female

$\times$ not state

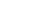

gender

Omale

$\triangle$ female

gender

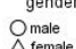

$\underset{\triangle \text { female }}{ }$

$\times$ not stated

\section{Figure 2}

Period prevalence data expressed by age range and gender. Data are not reported for prevalence of cervicothoracic and thoracolumbar pain (4 studies). In studies where an age range was reported, the median age was calculated for the 'age range' variable. Studies reporting only a minimum age for inclusion were excluded from the Figure $[5 I, 56]$. Therefore, the Figure shows data from five studies which reported point prevalence, 6 for I-week prevalence, 6 for I-month prevalence, I for 3month prevalence, 6 for I-year prevalence, and 3 for lifetime prevalence. 
justification, with only 2 (6.1\%) studies addressing this criterion with a power calculation. However, in observational studies concerning prevalence and incidence a sample size estimate is not as critical as in intervention studies, since demonstrating a difference between groups is rarely needed. We acknowledge, however, that power is needed in order to detect relationships in epidemiologic studies. The independent reviewers also identified biases in many studies, primarily related to sampling bias. We considered a sample bias to be present if the response rate to a questionnaire was less than $80 \%$ [70]. Finally, only $33.3 \%$ and $42.4 \%$ of the included studies presented evidence about the validity and reliability, respectively, of the outcome measures used. The comprehensive quality assessments performed in this study highlight areas for improvement in research design and reporting in the context of spinal pain.

\section{TSP prevalence}

The range of prevalence estimates of TSP in the general population was broad. Similarly, a broad range of TSP prevalence was reported in a review of TSP among adult working populations [7]. The wide prevalence range is partially a reflection of the influence of age and gender. However, even within an age range and gender category, prevalence estimates were highly variable. For example, point prevalence in children ranged from $14-38 \%$ among males (based upon 2 studies) and 9-72\% among females ( 2 studies). This may result from the variable operational definitions or study inclusion criteria for pain cases in cross-sectional studies. Notably, the studies on young people were often focussed on pain related to school bags and workstations which may also have influenced the reported rates. The operational definition issue has been identified as a major limitation in the comparability between prevalence studies in low back pain research [29].

Variability in operational definitions of TSP may also influence the interpretation of TSP across prevalence periods. As highlighted in Figure 2, children had higher TSP prevalence than adults for one month prevalence, while the reverse was observed for one year prevalence. This inconsistency may partly be explained by recall period, where children are less likely to recall events over a longer duration. However, a more likely explanation may be the differences in operational definitions of TSP between studies. Data for one month prevalence of TSP in youth was sourced from four studies $[11,50,57,67]$ while only one study was available for adult data [55]. The operational definition for TSP in the adult study was "frequent pain in the upper back" compared to "any pain" or "pain duration $\geq 1$ day" in the youth studies. Fewer adults were likely to report frequent pain as compared to definitions that were unrelated to pain frequency. Similarly, for the one year prevalence, six adult studies contributed to the data and adopted a definition of "any pain" $[13,46,47,68]$, "pain duration for $\geq 1$ week" [51], or "pain after work" [39], while one youth study reported a definition of "pain interfering with school or leisure" [45]. The lower prevalence in the youth study was likely related to a definition of pain which needed to be associated with a functional impairment.

To assess the effect of study quality on the prevalence ranges we excluded the 8 studies which scored less than the mean method-quality score $(<10 / 15)$. Excluding these studies had a minimal effect on prevalence other than raising the lower limit of 7-day prevalence to $2.8 \%$ (from $0.5 \%$ ), raising the lower limit of 1-year prevalence to $15.0 \%$ (from $3.5 \%$ ), and leaving one study reporting a lifetime prevalence of $15.6 \%$ (from 15.6-19.5\%). This finding is consistent with an earlier study which reported prevalence estimates of neck pain to be unrelated to study quality [71]. We did not perform a similar sensitivity analysis based on NHMRC Hierarchy of Evidence rank since the majority of studies were ranked as level IV, thus over representing this type of study design relative to others.

We identified 6 prevalence periods and 4 incidence periods in the literature for TSP. Prevalence data were distributed relatively equally across the 6 periods, other than the 3 month period where only one report of TSP prevalence was made in one study [66]. Therefore, it seems that there is not only a lack of consensus with respect to definitions of pain and inclusion criteria between studies, but also the most appropriate prevalence period to investigate. The $7-$ day and 1-year prevalence periods were the most commonly reported $(25.8 \%$ and $22.6 \%$ respectively), consistent with an earlier systematic review of neck pain [71]. Moreover, they are also consistent with recall periods in the Nordic Musculoskeletal Pain Questionnaire [72], which is one of the most commonly used assessment tools in musculoskeletal research. Although recall bias may be more problematic with longer recall periods (e.g. 1-year) [73], shorter time frames (e.g. 7-day) may miss episodes of pain. In light of evidence which supports the validity of recalling pain intensity for at least a 3-month recall period [29], we suggest that for chronic and disabling spinal pain, recall bias is less likely to be threatened. Nevertheless, such variability in definitions renders interpretation of the data somewhat difficult, and this issue has been highlighted previously as a limitation in the comparability of spinal pain research [27-29,71]. A recent international Delphi study concluded that definitions for prevalence studies on low back pain should include, at a minimum, the site of low back pain, symptoms observed, time frame of the measure, and severity [29]. Arguably, these same criteria should be applied to TSP studies. Consistent with the consensus of an international working party for low back pain research [29], we recommend a 1 month prevalence period for studies investigating TSP. 
Similar to findings in this review, prevalence estimates for low back and neck pain vary widely in the literature. Among the general adult population, the point, 12-month and lifetime prevalence for low back pain ranges from $5.6-28.4 \%, 22-65 \%$, and $11-84 \%$ across various studies $[46,74-76]$, while for neck pain these estimates are 5.9$38.7 \%, 16.7-75.1 \%$, and $0.2-71 \%$ across various studies $[71,77]$ and for TSP the 12-month prevalence ranges from $15-34.8 \%[13,46,47,51,68]$. Notwithstanding the wide prevalence ranges and variability of spinal pain definition, it appears that TSP may be a significant a problem in adulthood. In adolescents the point, 12-month and lifetime prevalence for low back pain ranges from 1.0$35.8 \%, 7.0-50.8 \%$, and $7.0-72.0 \%$ respectively [25] and for neck pain the 12-month and lifetime prevalence range from $7.6-13.0 \%$ and $3.0-28.0 \%$ respectively [25]. In this review the point, 12-month and lifetime for TSP in adolescents (13-20 years) was reported to range from 4.0$41.0 \%, 4.2-9.7 \%$, and $15.6-19.5 \%$ suggesting comparable significance to low back and neck pain in adolescents. Notably, the point prevalence for TSP in children was even higher (4.0-72.0\%), suggesting the magnitude of the problem of TSP, in terms of prevalence, to be greatest in youth. This may be one reason why there are a greater number of studies using childhood and adolescent cohorts compared to adult cohorts. However, further interpretation of the impact of TSP should be made with due consideration to the severity and disability associated with the experience of TSP.

Higher TSP prevalence in females is consistent with general reports of musculoskeletal pain in adults [78], adolescents $[79,80]$ and children [81]. A higher prevalence of self-reported pain among females may be due to differences in physical activity, musculoskeletal maturity, posture, endocrine and psychosocial characteristics as well as different physiological mechanisms for pain perception between genders [82], which should be investigated.

\section{TSP Incidence}

Interpretation of incidence data is limited due to the small number of studies that report TSP incidence. The method quality of these studies was generally high (range: 9/1513/15). Excluding the one study with a quality score below the mean did not significantly change the interpretation of TSP incidence other than excluding the report of 25 -year incidence [62]. However, as with prevalence data, there was considerable variability in the pain definitions and incidence periods, and females generally experienced a higher incidence of TSP, except during late adolescence.

\section{TSP burden}

Unlike neck and low back pain, the burden of TSP has not been well established, which represents an important avenue for future research. Within a cohort of Danish chil- dren and adolescents, TSP was the most commonly reported site of spinal pain and 38\% of the cohort reported some kind of impact from spinal pain, such as reduced physical activity and care-seeking [11]. Similarly, in a cohort of adults reporting TSP, $23.5 \%$ reported difficulty with activities of daily living due to pain (compared to $30.3 \%$ and $41.1 \%$ for neck and low back pain respectively) while the median (IQR) for the number of days where pain was experienced during activities of daily living was 13.5 (5.0-30.0) for TSP, 7.0 (3.0-30.0) for neck pain and $10.0(4.0-30.0)$ for low back pain [13]. Moreover, TSP has been identified as a significant predictor of failure of returning to work in good health among individuals who present with back pain in primary care [23]. Collectively, these data suggest that TSP imparts an impact comparable to neck and low back pain.

\section{Associated factors and risk factors for TSP}

In children and adolescents, TSP was associated with female gender, postural changes associated with backpack use, backpack weight, other musculoskeletal symptoms, participation in specific sports, chair height at school, and difficulty with homework, while poorer mental health and age transition from early to late adolescence were significant risk factors for TSP. In adults TSP was associated with concurrent musculoskeletal symptoms and difficulty in performing activities of daily living and there were no studies reporting risk factors. Although the limited data describing the associated and risk factors for TSP established predominantly with bivariate analyses render interpretation of its aetiology difficult, the factors identified in this review suggest that musculoskeletal growth, biomechanical loading, concurrent musculoskeletal pain and psychosocial characteristics are important mediators. Therefore, a biopsychosocial framework would seem appropriate for conceptualising TSP aetiology among the general population who are free of other pathology.

\section{Strengths and limitations}

Strengths of this review include a systematic review method, in particular the use of an appropriate critical appraisal tool for observational epidemiological literature. Additionally, tailoring of the search strategy, via the use of broad search terms, was employed to capture studies that reported on the prevalence, incidence or risk of TSP even where these parameters were not the study's primary objective. This search approach formed the rationale of an earlier review [71]. However, the findings presented here should be interpreted within the limitations of the review. Firstly, the studies included were generally from high income countries and therefore the data reported may not represent TSP from a global perspective [83]. Future studies should examine whether any differences exist in TSP experiences between ethnic groups. Secondly, studies published in languages other than English were 
not reviewed. Thirdly, studies reporting epidemiologic data for TSP in discrete occupational groups were not included, as risk factors for spinal pain would likely be influenced by, and differ between occupations and not be representative of the general population. Finally, studies in this review involving children and adolescents were derived from samples of schoolchildren and therefore do not represent children who do not attend school, for example those involved in child labour [84]

\section{Conclusion}

The information presented in this systematic review confirms a relatively high prevalence of TSP in the general population and substantiate the view that TSP is a discrete and important clinical condition. Considering the high reported prevalence estimates for TSP and relatively scarce information concerning risk factors, further research should be directed towards the epidemiology of TSP, particularly in adolescence, using prospective cohort designs. Careful consideration should be given to minimising sampling bias and using valid and reliable outcome measures. Furthermore, it will be important for future studies to use a consistent and appropriate definition of TSP, and specifically avoid using simply 'back pain' as an outcome variable, a recommendation endorsed by a recent international consensus [29]. Moreover, an exploration of prognostic factors should include psychological, physical, occupational and social mediators of TSP [85].

\section{Competing interests}

The authors declare that they have no competing interests.

\section{Authors' contributions}

$\mathrm{AB}$ developed the research question, coordinated the review, contributed to the research design, performed the literature search, performed data extraction, and contributed to study selection, quality appraisal and manuscript writing. AS contributed to study selection, quality appraisal and manuscript writing. LS contributed to the research question and manuscript writing. $\mathrm{PB}$ contributed to the research question, research design, quality appraisal and manuscript writing. All authors read and approved the final manuscript.

\section{Authors' information}

$\mathrm{AB}$ is a clinical physiotherapist and NHMRC postdoctoral research fellow. AS is an NHMRC postdoctoral research fellow and physiotherapist. LS is a professor, NHMRC senior research fellow and physiotherapist. $\mathrm{PB}$ is a research fellow and physiotherapist.

\section{Appendix I}

Search strings used in electronic databases. The * symbol indicates truncation for the search term.

\section{Population}

child* or adult* or worker* or adolescent* or schoolchild $^{*}$ or student* or profession* ${ }^{*}$ or pediatric or paediatric

AND

\section{Location}

thoracic spine or dorsal spine or mid* back or upper back or thoracolumbar or cervicothoracic

AND

\section{Condition}

pain or discomfort or back pain or musculoskeletal disorder* or dysfunction or disability or disabilities or musculoskeletal disease or injur* or occupational disease or occupational disorder

AND

\section{Study}

causality or cohort stud* or cross-sectional stud* or epidemiolog* or epidemiologic factor* or follow-up study or incidence or incidence studies or prevalence or prevalence studies or prospective studies or risk or risk factor or survey

\section{Limits}

English language, human studies, fields (title or abstract)

\section{Exclusion terms (NOT)}

surgery or surgical or operative or fracture or osteoporosis

\section{Complete search strategy using * truncation}

(child* OR adult* OR worker* OR adolescent* OR schoolchild* OR student* OR profession* OR pediatric OR paediatric) AND (thoracic spine OR dorsal spine OR mid* back OR upper back OR thoracolumbar OR cervicothoracic) AND (pain OR discomfort or back pain OR musculoskeletal disorder* OR dysfunction OR disability OR disabilities OR musculoskeletal disease OR injur* OR occupational disease OR occupational disorder) AND (causality OR cohort stud* OR cross-sectional stud* OR epidemiolog* OR epidemiologic factor* OR follow-up study OR incidence OR incidence studies OR prevalence OR prevalence studies OR prospective studies OR risk OR risk factor OR survey) NOT (surgery OR surgical OR operative OR fracture* OR osteoporo*)

Complete search strategy for PubMed

(child OR children OR childhood OR adult OR adults OR adulthood OR worker* OR adolescent* OR schoolchild* OR student* OR profession* OR pediatric* OR paediatric* OR pediatrics) AND (thoracic spine OR dorsal spine 
OR "mid back" OR "midback" OR "middle back" OR "upper back" OR thoracolumbar OR cervicothoracic) AND (pain OR discomfort OR back pain OR back ache OR backache OR musculoskeletal disorder* OR dysfunction OR disability OR disabilities OR musculoskeletal disease OR injury OR injuries OR injured OR occupational disease OR occupational disorder*) AND (causality OR cohort stud* OR cross-sectional stud* OR epidemiolog* OR epidemiologic factor* OR follow-up study OR incidence OR incidence studies OR prevalence OR prevalence studies OR prospective studies OR risk OR risk factor OR survey OR surveys) NOT (surgery OR surgical OR operative OR fracture* OR osteoporo* OR surgical procedures, operative)

\section{Abridged search strings}

Thoracic spine or dorsal spine or mid \$ back or upper back

AND

Pain or disorder* or injur*

\section{Appendix 2}

NHMRC Evidence Hierarchy: designations of levels of evidence according to Aetiologyresearch questions.

\section{Level - Descriptor}

I - A systematic review of level II studies

II - A prospective cohort study

III-1 - All or none*

III-2 - A retrospective cohort study

III-3 - A case-control study

IV - A cross-sectional study or case series

* all or none of the people with the risk factor(s) experience the outcome; the data arises from an unselected or representative case-series which provides an unbiased representation of the prognostic effect.

The complete levels of evidence document may be viewed at http://www.nhmrc.gov.au/guidelines/consult/consul tations/add levels grades dev guidelines $2 . \mathrm{htm}$

\section{Appendix 3}

Database search results

\section{Database - First search date - Citations}

Medline - 8-Jan-08 - 174

\author{
CINAHL - 8-Jan-08 - 760 \\ PubMed - 9-Jan-08 - 211 \\ ISI Web of Science - 8-Jan-08 - 443 \\ BioMed Central - 9-Jan-08 - 4 \\ PEDro - 8-Jan-08 - 64 \\ EMBASE - 9-Jan-08 - 53 \\ Cochrane - 8-Jan-08 - 1 \\ AMED - 8-Jan-08 - 15 \\ SUM $=1725$ \\ Duplication $=-336$ \\ Citations for review $=1389$
}

\section{Additional material}

Additional File 1

Cohort characteristics, TSP data source, hierarchy of evidence score and quality appraisal for each study. The data provided describe the characteristics of each paper included in the review and results of the quality appraisal.

Click here for file

[http://www.biomedcentral.com/content/supplementary/14712474-10-77-S1.pdf]

\section{Additional File 2}

Prevalence (29 studies) and incidence (5 studies) data grouped by pain definition and reported by age. The data provided describe the prevalence and incidence of TSP across the included studies. Click here for file [http://www.biomedcentral.com/content/supplementary/14712474-10-77-S2.pdf]

\section{Additional File 3}

Associated (cross-sectional studies) and risk (prospective studies) factors for TSP grouped according to biopsychosocial categories. Estimates are expressed as an odds ratio $(95 \% \mathrm{CI})$ unless indicated otherwise. An OR $>1$ refers to a positive association with TSP, while and $\mathrm{OR}<1$ refers to a negative association. Where correlation coefficients are reported, positive values represent a positive association with TSP, while negative values represent a negative association. For statistical tests which do not test for association, a significant outcome $(p<0.05)$ refers to the factor being greater among individuals with TSP. The data provided summarise factors associated with, and risk factors for TSP.

Click here for file

[http://www.biomedcentral.com/content/supplementary/14712474-10-77-S3.pdf] 


\section{Acknowledgements}

The authors gratefully acknowledge Jay-Shian Tan for providing administrative assistance. Dr Briggs, Dr Smith and Professor Straker are supported by fellowships awarded by the National Health and Medical Research Council (NHMRC) of Australia.

\section{References}

I. Carragee EJ, Alamin TF, Miller JL, Carragee JM: Discographic, MRI and psychosocial determinants of low back pain disability and remission: a prospective study in subjects with benign persistent back pain. Spine Journal 2005, 5:24-35.

2. Hill JC, Lewis M, Sim J, Hay EM, Dziedzic K: Predictors of poor outcome in patients with neck pain treated by physical therapy. Clin J Pain 2007, 23:683-90.

3. Australian Acute Musculoskeletal Pain Guidelines Group: Evidencebased management of acute musculoskeletal pain. A guide for clinicians. Brisbane: Australian Academic Press. National Health and Medical Research Council (Australia); 2004.

4. Edmondston SJ, Singer KP: Thoracic spine: anatomical and biomechanical considerations for manual therapy. Man Ther 1997, 2:132-143.

5. Austin GP, Benesky WT: Thoracic pain in a collegiate runner. Man Ther 2000, 7:168-172.

6. Briggs AM, Straker LM: Thoracic spine pain in youth: Should we be concerned? Spine Journal 2009, 9:338-339.

7. Briggs AM, Bragge P, Smith AJ, Govil D, Straker LM: Prevalence and associated factors for thoracic spine pain in the adult working population. A literature review. J Occup Health 2009, 5 I:177-192.

8. Fruth SJ: Differential diagnosis and treatment in a patient with posterior upper thoracic pain. Phys Ther 2006, 86:254-268.

9. Fukui S, Ohseto K, Shiotani M: Patterns of pain induced by distending the thoracic zygapophyseal joints. Reg Anesthesia 1997, 22:332-336.

10. Singer KP: Pathology of the thoracic spine. In Clinical Anatomy and Management of Thoracic Spine Pain. The Clinical Anatomy and Management of Back Pain Series Edited by: Giles LGF, Singer KP. Oxford: Butterworth Heinmann; 2000:63-82.

II. Wedderkopp N, Leboeuf-Yde C, Andersen LB, Froberg K, Hansen $\mathrm{HS}$ : Back pain reporting pattern in a Danish population-based sample of children and adolescents. Spine 200I, 26: |879- I883.

12. Grimmer K, Nyland L, Milanese S: Repeated measures of recent headache, neck and upper back pain in Australian adolescents. Cephalgia 2006, 26:843-85I.

13. Niemelainen R, Videman T, Battie MC: Prevalence and characteristics of upper or mid-back pain in Finnish men. Spine 2006, 31:1846-9.

14. Hakala P, Rimpela A, Salminen JJ, Virtanen SM, Rimpela M: Back, neck and shoulder pain in Finnish adolescents: National cross sectional surveys. Brit Med J 2002, 325:743-745.

15. Briggs AM, Greig AM, Wark JD: The vertebral fracture cascade in osteoporosis. A review of aetiopathogenesis. Osteoporos Int 2007, 18:575-584.

16. Cockerill WC, Ismail AA, Cooper C, Matthis C, Raspe H, Silman AJ, O'Neill TW: Does location of vertebral deformity within the spine influence back pain and disability? European Vertebral Osteoporosis Study (EVOS) Group. Ann Rheum Dis 2000, 59:368-37।.

17. Ettinger B, Black D, Nevitt MC, Rundle AM, Cauley JA, Cummings SR, Genant HK: Contribution of vertebral deformities to chronic back pain and disability. J Bone Miner Res 1992, 7:449-455.

18. Johansson C, Mellstrom D, Rosengren K, Rundgren A: A community based population study of vertebral fractures in 85 year old men and women. Age and Ageing 1994, 23:388-392.

19. Kado DM, Prenovost K, Crandall C: Narrative review: Hyperkyphosis in older persons. Ann Int Med 2007, I 47:330-338.

20. Sampaio-Barros PD, Bertolo MB, Kraemer MHS, Neto JFM, Samara AM: Primary ankylosing spondylitis: Patterns of disease in a Brazilian population of I47 patients. J Rheum 200I, 28:560-565.

21. Kramer PA: Prevalence and distribution of spinal osteoarthritis in women. Spine 2006, 31:2843-2848.

22. Murray PM, Weinstein SL, Spratt KF: The natural history and long term follow-up of Scheuermann kyphosis. J Bone Joint Surg (American) 1993, 75A:236-248.
23. Dionne CE, Bourbonnais R, Fremont $P$, Rossignol M, Stock SR, Nouwen A, Larocque I, Demers E: Determinants of "return to work in good health" among workers with back pain who consult in primary care settings: A 2-year prospective study. Eur Spine J 2007, 16:64I-655.

24. Wood KB, Garvey TA, Gundry C, Heithoff KB: Magnetic resonance imaging of the thoracic spine. J Bone Joint Surg (American) 1995, 77A:1631-1638.

25. Jeffries LJ, Milanese SF, Grimmer-Somers KA: Epidemiology of adolescent spinal pain. A systematic overview of the research literature. Spine 2007, 32:2630-2637.

26. Ariëns GAM, van Mechelen W, Bongers PM, Bouter LM, Wal G van der: Physical risk factors for neck pain. Scand J Work Environ Health 2000, 26:7-19.

27. Watson KD, Papageorgiou AC, Jones GT, Taylor S, Symmons DPM, Silman AJ, Macfarlane GJ: Low back pain in schoolchildren: occurrence and characteristics. Pain 2002, 97:87-92.

28. Balague F, Troussier B, Salminen JJ: Non-specific low back in children and adolescents: risk factors. Eur Spine J 1999, 8:429-438.

29. Dionne CE, Dunn KM, Croft PR, Nachemson AL, Buchbinder R, Walker BF, Wyatt M, Cassidy JD, Rossignol M, Leboeuf-Yde C, Hartvigsen J, Leino-Arjas P, Latza U, Reis S, del Real MTG, Kovacs FM, Oberg B, Cedraschi C, Bouter LM, Koes BW, Picavet HSJ, van Tulder MW, Burton K, Foster NE, Macfarlane GJ, Thomas E, Underwood M, Waddell G, Shekelle P, Volinn E, Von Korff M: A consensus approach toward the standardization of back pain definitions for use in prevalence studies. Spine 2008, 33:95-103.

30. Jones T, Evans D: Conducting a systematic review. Aust Crit Care 2000, I3:66-7I.

31. Guyatt GH, Sinclair J, Cook DJ, Glasziou P: User's guide to the medical literature: XVI. How to use a treatment recommendation. Evidence-Based Medicine Working Group and the Cochrane Applicability Methods Working Group. J Amer Med Assoc 1999, 28I: 1836-1843.

32. Stroup DS, Berlin JA, Morton SC, Olkin I, Williamson GD, Rennie D, Moher D, Becker BJ, Sipe TA, Thacker SB: Meta-analysis of observational studies in epidemiology. A proposal for reporting. Amer Med Assoc 2000, 283:2008-20I2.

33. Bragge $P$, Bialocerkowski A, McMeeken J: A systematic review of prevalence and risk factors associated with playing-related musculoskeletal disorders in pianists. Occup Med (Oxford) 2006, 56:28-38.

34. Elwood MJ: Critical Appraisal of Epidemiological Studies and Clinical Trials. 2nd edition. Oxford: Oxford University Press; 1998.

35. National Health and Medical Research Council: NHMRC additional levels of evidence and grades for recommendations for developers of guidelines. 2008 [http://www.nhmrc.gov.au/guide lines/consult/consultations/add levels grades dev guidelines $2 . \mathrm{htm}$ ]. Canberra: NHMRC

36. Law M, Stewart D, Letts L, Pollok N, Bosch J, Westmorland M: Guidelines for Critical Review Form - Quantitative Studies. 1998 [http://www.srs-mcmaster.ca/ResearchResourcesnbsp/Centre forEvidenceBasedRehabilitation/EvidenceBasedPracticeResearchoup/ tabid/630/Default.aspx]

37. Sanderson S, Tatt ID, Higgins JPT: Tools for assessing the quality and susceptibility to bias in observational studies: $A$ systematic review and annotated bibliography. Int J Epidemiol 2007, 36:666-676.

38. Bialocerkowski AE, Vladusic SL, Ng C: Prevalence, risk factors, and natural history of plagiocephaly: A systematic review. Develop Med Child Neurol 2008, 50:577-586.

39. Aronsson G, Gustafsson K, Dallner M: Sick but yet at work. An empirical study of sickness presenteeism. J Epidemiol Community Health 2000, 54:502-509.

40. Cudre Mauroux N, Kocher N, Bonfils R, Pirlet M, Meichtry A, Hilfiker $R$ : Relationship between impaired functional stability and back pain in children: An exploratory cross-sectional study. Swiss Med Weekly 2006, 136:72I-725.

4I. El-Metwally A, Salminen J], Auvinen A, Macfarlane G, Mikkelsson M: Risk factors for development of non-specific musculoskeletal pain in preteens and early adolescents: a prospective I-year follow-up study. BMC Musculoskel Disord 2007, 8:46.

42. Fairbank JCT, Pynsent PB, van Poortvliet JA, Phillips H: Influence of anthropometric factors and joint laxity in the incidence of adolescent back pain. Spine 1984, 9:461-464. 
43. Hagen K, Svebak S, Zwart JA: Incidence of musculoskeletal complaints in a large adult Norwegian county population. The HUNT Study. Spine 2006, 31:2146-2। 50.

44. Korovessis P, Koureas G, Zacharatos S, Papazisis Z: Backpacks, back pain, sagittal spinal curves and trunk alignment in adolescents: a logistic and multinomial logistic analysis. Spine 2005, 30:247-55.

45. Kujala UM, Taimela S, Viljanen T: Leisure physical activity and various pain symptoms among adolescents. Brit J of Sports Med 1999, 33:325-328.

46. Linton SJ, Hellsing A, Hallden K: A population-based study of spinal pain among 35-45-year-old individuals: prevalence, sick leave, and health care use. Spine 1998, 23:|457-63.

47. Linton SJ, Ryberg M: Do epidemiological results replicate? The prevalence and health-economic consequences of neck and back pain in the general population. Eur J Pain 2000, 4:347-354.

48. Moore MJ, White GL, Moore DL: Association of relative backpack weight with reported pain, pain sites, medical utilization, and lost school time in children and adolescents. J School Health 2007, 77:232-239.

49. Murphy S, Buckle P, Stubbs D: Classroom posture and selfreported back and neck pain in schoolchildren. Applied Ergon 2004, 35: I I3- I 20.

50. Murphy S, Buckle P, Stubbs D: A cross-sectional study of selfreported back and neck pain among English schoolchildren and associated physical and psychological risk factors. Applied Ergon 2007, 38:797-804.

5I. Park H, Sprince NL, Whitten PS, Burmeister LF, Zwerling C: Risk factors for back pain among male farmers: analysis of lowa Farm Family Health and Hazard Surveillance Study. Am J Ind Med 200I, 40:646-54

52. Reigo T, Timpka T, Tropp $\mathrm{H}$ : The epidemiology of back pain in vocational age groups. Scand J Primary Health Care 1999, I 7: I7-2I

53. Salminen Jl: The adolescent back. A field survey of $\mathbf{3 7 0}$ Finnish schoolchildren. Acta Paediatr Scand Suppl 1984, 3 I 5: I- I 22

54. Troussier B, Marchou-Lopez S, Pironneau S, Alais E, Grison J, Prel G, Pequegnot $C$, Degaudemaris $R$, Phelip $X$ : Back pain and spina alignment abnormalities in schoolchildren. Rev Rhum Engl Ed 1999, 66:370-80.

55. Tsuritani I, Honda R, Noborisaka Y, Ishida M, Ishizaki M, Yamada $Y$ Impact of obesity on musculoskeletal pain and difficulty of daily movements in Japanese middle-aged women. Maturitas 2002, 42:23-30.

56. Veerapen K, Wigley RD, Valkenburg $\mathrm{H}$ : Musculoskeletal pain in Malaysia: a COPCORD survey. J Rheum 2007, 34:207-2I 3.

57. Wedderkopp N, Andersen LB, Froberg K, Leboeuf-Yde C: Back pain reporting in young girls appears to be puberty-related. BMC Musculoskel Disord 2005, 6:52.

58. Whittfield J, Legg SJ, Hedderley DI: Schoolbag weight and musculoskeletal symptoms in New Zealand secondary schools. Applied Ergon 2005, 36:193-198.

59. Balague F, Damidot $P$, Nordin M, Parnianpour $M$, Waldburger $M$ : Cross-sectional study of the isokinetic muscle trunk strength among school children. Spine 1993, I 8: I I99-I 205.

60. Balague F, Dutoit G, Waldburger M: Low back pain in schoolchildren. An epidemiological study. Scand J Rehabil Med 1988, 20:175-179.

61. Balague F, Skovron ML, Nordin M, Dutoit G, Waldburger M: Low back pain in schoolchildren: A study of familial and psychologic factors. Spine 1995, 20:1265-1270.

62. Dieck GS, Kelsey JL, Goel VK, Panjabi MM, Walter SD, Laprade MH: An epidemiologic study of the relationship between postural asymmetry in the teen years and subsequent back and neck pain. Spine 1985, 10:872-877.

63. Ehrmann Feldman D, Shrier I, Rossignol M, Abenhaim L: Risk factors for the development of neck and upper limb pain in adolescents. Spine 2002, 27:523-528.

64. Harreby M, Nygaard B, Jessen T, Larsen E, Storr-Paulsen A, Lindahl A, Fisker I, Laegaard E: Risk factors for low back pain in a cohort of I389 Danish schoolchildren: An epidemiologic study. Eur Spine 1999, 8:444-450.

65. Korovessis P, Koureas G, Papazisis Z: Correlation between backpack weight and way of carrying, sagittal and frontal spinal curvatures, athletic activity, and dorsal and low back pain in schoolchildren and adolescents. J Spinal Disord Tech 2004 17:33-40.
66. Mikkelsson M, Salminen Jl, Kautiainen H: Non-specific musculoskeletal pain in preadolescents. Prevalence and I-year persistence. Pain 1997, 73:29-35.

67. Mogensen AM, Gausel AM, Wedderkopp N, Kjaer P, Leboeuf-Yde C Is active participation in specific sport activities linked with back pain? Scand J Med Sci Sports 2007, I 7:680-686.

68. Natvig B, Nessioy I, Bruusgaard D, Rutle O: Musculoskeletal symptoms in a local community. Eur J Gen Prac 1995, I:25-28.

69. Feldman DE, Shrier I, Rossignol M, Abenhaim L: Risk factors for the development of neck and upper limb pain in adolescents. Spine 2002, 27:523-528.

70. Partin MR, Malone M, Winnett M, Slater J, Bar-Cohen A, Caplan L: The impact of survey nonresponse bias on conclusions drawn from a mammography intervention trial. J Clin Epidemiol 2003, 56:867-873.

7I. Fejer R, Kyvik KO, Hartvigsen J: The prevalence of neck pain in the world population: A systematic critical review of the literature. Eur Spine J 2006, I 5:834-848.

72. Kuorinka I, Jonsson B, Kilbom A, Vinterverg H, Biering-Sorensen F, Andersson G, Jorgensen K: Standardised Nordic questionnaires for the analysis of musculoskeletal symptoms. Applied Ergon 1987, 18:233-237.

73. Orhede E: Nordic cooperation in research on the work environment. Scand J Work Environ Health 1994, 20:65-66.

74. Cassidy JD, Carroll LJ, Cote P: The Saskatchewan Health and Back Pain Survey: the prevalence of low back pain and related disability in Saskatchewan adults. Spine 1998, 23: $1860-7$.

75. Loney PSP: The prevalence of low back pain in adults: A methodological review of the literature. Phys Ther 1999, 79:384-396.

76. Walker BF, Muller R, Grant WD: Low back pain in Australian adults. Prevalence and associated disability. J Manip Physio Therap 2004, 27:238-244

77. Hogg-Johnson S, Velde G van der, Carroll LJ, Holm LW, Cassidy JD, Guzman J, Cote P, Haldeman S, Ammendolia C, Carragee E, Hurwitz $E$, Nordin $M$, Peloso $P$ : The burden and determinants of neck pain in the general population. Results of the bone and joint decade 2000-20 I 0 task force on neck pain and its associated disorders. Spine 2008, 33:S39-S5I.

78. Wijnhoven HA, de Vet HCW, Picavet HSJ: Prevalence of musculoskeletal disorders is systematically higher in women than in men. Clin J Pain 2006, 22:717-724.

79. Adamson G, Murphy S, Shevlin M, Buckle P, Stubbs D: Profiling schoolchildren in pain and associated demographic and behavioural factors: A latent class approach. Pain 2007, I 29:295-303.

80. Kovacs FM, Gestoso M, del Real MTG, Lopez J, Mufraggi N, Mendez II: Risk factors for non-specific low back pain in schoolchildren and their parents: a population based study. Pain 2003, 103:259-268.

81. De Inocencio J: Epidemiology of musculoskeletal pain in primary care. Arch Dis Childhood 2004, 89:43 I-434.

82. LeResche L: Gender considerations in the epidemiology of chronic pain. In Epidemiology of Pain Edited by: Crombie IK, Croft PR, Linton Sj, LeResche L, Von Korff M. Seattle: IASP; 1999:43-52.

83. Volinn E: The epidemiology of low back pain in the rest of the world. A review of surveys in low and middle income countries. Spine 1997, 22:1747-1754.

84. Fassa AG, Facchini LA, Mor Dall'Agnol M, Christiani D: Child labor and musculoskeletal disorders: The Pelotas (Brazil) epidemiological survey. Pub Health Reports 2005, I 20:665-673.

85. Windt $D$ van der, Hay E, Jellema $P$, Main C: Psychosocial interventions for low back pain in primary care - Lessons learned from recent trials. Spine 2008, 33:81-89.

\section{Pre-publication history}

The pre-publication history for this paper can be accessed here:

http://www.biomedcentral.com/1471-2474/10/77/pre pub 